\title{
MENINGKATKAN KEMAMPUAN MENYANYIKAN LAGU INDONESIA RAYA MELALUI GABUNGAN TEKNIK FILM DAN DEMONSTRASI TERHADAP SISWA KELAS XI 3 DI SMA NEGERI 2 NGAWI TAHUN PELAJARAN 2018/2019
}

\author{
ANA ARY SETYANINGIH \\ SMA Negeri 2 Ngawi \\ e-mail: ana.arysetyaningsih@gmail.com
}

\begin{abstract}
ABSTRAK
Penelitian ini menggunakan tindakan kelas dengan model Gabungan Teknik Film dan Demonstrasi. Lewat film, informasi dapat disampaikan secara mendalam. Media ini banyak digemari orang karena dapat dijadikan sebagai hiburan dan penyalur hobby. Selain itu, juga sebagai media pendidikan maupun menyampaikan pesan kepada masyarakat. Sedangkan metode demonstrasi merupakan cara pembelajaran dengan memperagakan atau mempertunjukan kepada siswa suatu proses, situasi, benda, atau cara kerja suatu produk teknologi yang sedang dipelajari yang bertujuan agar peserta didik memperoleh pengalaman belajar secara langsung setelah melihat, melakukan dan merasakan. Hasil dari tindakan kelas ini dapat dikatakan berhasil hal ini dapat dilihat dari semakin mantapnya pemahaman siswa terhadap materi yang disampaikan guru (rata-rata kelas dari siklus I dan ke II) yaitu masingmasing 78,89 dan 80,69. Pada siklus II kelas dalam keadaan tuntas.
\end{abstract}

Kata Kunci: Penelitian Tindakan Kelas, Film, Dokumentasi.

\section{PENDAHULUAN}

Lagu Indonesia Raya merupakan lagu kebangsaan bangsa Indonesia. Lagu Indonesia Raya dinyanyikan pada setiap upacara bendera. Di SMA Negeri 2 Ngawi Lagu Indonesia Raya bukan hanya dinyanyikan pada setiap upacara bendera, namun juga dinyanyikan pada setiap awal jam pelajaran pertama. Oleh karena itu, setiap siswa diharapkan dapat menyanyikan lagu tersebut dengan baik dan benar.

Pada kenyataannya, hal tersebut di atas masih belum sepenuhnya terlaksana. Berdasarkan pengamatan terhadap siswa kelas XI 3 SMA Negeri 2 Ngawi Semester 1 Tahun pelajaran 2018/2019, bahwa pada pembelajaran seni budaya pada materi "Menyanyikan Lagu Indonesia Raya" siswa mengalami kesulitan belajar. Berdasarkan analisis hasil ulangan materi "Menyanyikan Lagu Indonesia Raya" pada mata pelajaran seni budaya Kelas XI 3 SMA Negeri 2 Ngawi Semester 1 Tahun pelajaran 2018/2019, diperoleh bahwa rata-rata kelas 75,28 atau ketuntasan untuk kemampuan menggelar pertunjukkan seni musik di kelas yaitu 61,11\%. Sehingga belum memenuhi KKM. Guru masih menggunakan pembelajaran konvensional alam membelajarkan Lagu Indonesia Raya pada siswa.

Rendahnya taraf serap siswa kelas XI 3 pada materi tersebut diduga karena belum mampu menyanyikan Lagu Indonesia Raya dengan baik dan benar. Hal tersebut terjadi karena siswa kurang dapat mengolah vokal, Untuk mengatasi permasalahan di atas, diperlukan pembelajaran yang memungkinkan mereka untuk mengilustrasikan ketrampilan dan teknik yang baru saja dibahas di kelas. Untuk sebab itu, penulis berusaha melakukan penelitian tindakan dengan model "Gabungan Teknik Film dan Demonstrasi".

Film adalah media yang sangat berpengaruh. Film melebihi media-media yang lain. Audio dan visual dalam Film dapat bekerja sama dengan baik hingga formatnya menarik. Oleh karena itu, penontonnya tidak bosan dan lebih mudah mengingat. Film digunakan sebagai media yang merefleksikan realitas atau bahkan sebagai pembentuk realitas. Cerita yang ditayangkan lewat film dapat berbentuk fiksi atau non fiksi. Lewat film, informasi dapat disampaikan secara mendalam. Media ini banyak digemari orang karena dapat dijadikan sebagai hiburan dan penyalur hobby. Selain itu, juga sebagai media pendidikan maupun menyampaikan pesan kepada masyarakat. 
Sedangkan metode demonstrasi merupakan cara pembelajaran dengan memperagakan atau mempertunjukan kepada siswa suatu proses, situasi, benda, atau cara kerja suatu produk teknologi yang sedang dipelajari yang bertujuan agar peserta didik memperoleh pengalaman belajar secara langsung setelah melihat, melakukan dan merasakan. Selama proses pembelajaran, siswa mengamati dan memperhatikan cara atau teknik dalam bernyanyi yang dilakukan oleh guru. Proses pembelajaran akan lebih berkesan dan memberikan motivasi yang kuat kepada siswa.(Sanjaya, 2006). Pembelajaran melalui media film dan demonstrasi diharapkan mampu menumbuhkan rasa cinta nasionalisme dan teknik vokal siswa Berdasarkan uraian tersebut di atas, penulis mengadakan penelitian pada siswa Kelas XI 3 SMA Negeri 2 Ngawi Semester 1 Tahun pelajaran 2018/2019. Penelitian yang dilaksanakan, berjudul "Meningkatkan Kemampuan Menyanyikan Lagu Indonesia Raya Melalui Gabungan Teknik Film dan Demonstrasi terhadap Siswa Kelas XI 3 SMA Negeri 2 Ngawi Tahun pelajaran 2018/2019".

\section{METODE PENELITIAN}

Penelitian ini menggunakan Penelitian Tindakan Kelas (PTK), tujuan utama dari PTK adalah untuk memperbaiki/meningkatkan praktek pembelajaran secara berkesinambungan, sedangkan tujuan penyertaannya adalah menumbuhkan budaya meneliti di kalangan guru.

Sesuai dengan jenis penelitian yang dipilih, yaitu penelitian tindakan, maka penelitian ini menggunakan model penelitian tindakan dari Kemmis dan Taggart, yaitu berbentuk spiral dari sklus yang satu ke siklus yang berikutnya. Setiap siklus meliputi planning (rencana), action (tindakan), observation (pengamatan), dan reflection (refleksi). Langkah pada siklus berikutnya adalah perencanaan yang sudah direvisi, tindakan, pengamatan, dan refleksi

\section{HASIL DAN PEMBAHASAN}

Sebelum Penelitian, peneliti telah mengadakan pembelajaran dengan metode tradisional (konvensional). Selanjutnya mengadakan tes, adapun hasil tes tersebut: Rata-rata kelas 75,28. Dari 36 siswa, yang tuntas 22 siswa dan yang tidak tuntas 14 siswa. Ini berarti ketuntasan kelas $61,11 \%$. Hal ini menunjukkan hasil belajar siswa secara klasikal belum tuntas.

\section{A. Siklus I}

\section{Perencanaan}

Uraian lengkap rencana pembelajaran terdapat pada lampiran. Disamping membuat RPP penulis: Menyiapkan sejumlah pertanyaan yang akan dilontarkan pada kelompok siswa dan menjelaskan pada siswa tentang tugas yang harus dikerjakan. Sedangkan diskusi dengan teman sejawat dilakukan untuk menentukan hari tanggal pelaksanaan pembelajaran siklus I. Selain itu diskusi tentang penyusunan lembar pengamatan, aspek-aspek yang perlu diamati.

\section{Tindakan}

\section{1) Kegiatan Awal}

Langkah pertama dalam metode ini adalah menginformasikan tentang kegiatan dan tujuan pembelajaran. Guru menyampaikan tentang sekilas tentang kegiatan pembelajaran yang meliputi garis besar langkah-langkahnya. Guru juga menyampaikan sekilas tentang tujuan pembelajaran. Siswa kurang memperhatikan apa yang disampaikan guru. Para siswa masih ada yang bergurau sendiri. Beberapa siswa bahkan ada yang ijin keluar dengan alasan ke belakang. Siswa kelihatan tidak termotivasi dengan adanya pembelajaran ini.

\section{2) Kegiatan Inti}

Langkah pertama dalam kegiatan ini adalah guru memutar Film Sejarah Lahirnya Indonesia Raya. Siswa memperhatikan tayangan Film Sejarah Lahirnya Indonesia Raya. Kemudian, guru mengadakan tanya jawab dengan Siswa. Guru kurang semangat dalam mengadakan tanya jawab dengan siswa Siswa kurang semangat dalam mengadakan tanya jawab dengan guru. 
Langkah selanjutnya dalam kegiatan ini adalah guru memutar Film Teknik Vokal. Siswa cukup memperhatikan tayangan Film Sejarah Teknik Vokal. Guru menjelaskan Teknik Vokal. Siswa cukup memperhatikan penjelasan Teknik Vokal yang siampaikan guru. Setelah menjelaskan Teknik Vokal, guru membagi siswa menjadi 7 kelompok masing-masing 5 atau 6 siswa. Siswa Membagi kelompok praktek vokal menjadi 7 kelompok masing-masing 6 atau 7 siswa (kelompok 1 sampai 6 terdiri 5 siswa, sedangkan kelompok 7 terdiri 6 siswa). Guru membagi siswa dalam kelompok berdasar nomor absen. Adapun nama-namanya:

Tabel 1. Nama Kelompok 1

\begin{tabular}{|l|l|}
\hline 1 & AANG ADRIAN FIRMANSYAH \\
\hline & $\begin{array}{l}\text { ANCHI ALIFIA AZZAHRA } \\
2\end{array}$ \\
\hline 3 & ANOVADIKA \\
\hline 4 & ANINDITO PUTRA WIBISONO \\
\hline 5 & ARUM PURSILASARI \\
\hline
\end{tabular}

Tabel 2. Nama Kelompok 2

\begin{tabular}{|l|l|}
\hline 6 & AYLUL FAJRINNIAR 'AINIYAH \\
\hline 7 & BILQIS SALMA GINTAJATI \\
\hline 8 & BINTANG DEWANTO \\
\hline 9 & BRIAN SYAFRIANSYAH \\
\hline 10 & DEA CARISSA OVILIA \\
\hline
\end{tabular}

Tabel 3. Nama Kelompok 3

\begin{tabular}{|l|l|}
\hline 11 & DELA BINTANG WULANDARI \\
\hline 12 & DHIMAS PANDU WIJAYA \\
\hline 13 & ELIYANO ATMAJA TIMUR \\
\hline 14 & ENJELLINA APRIANTI \\
\hline 15 & FERRY HENDRA WIJAYA \\
\hline
\end{tabular}

Tabel 4. Nama Kelompok 4

\begin{tabular}{|l|l|}
\hline 16 & FINA PRAMESTA \\
\hline 17 & FIRMANNANDA WIRA SUBAGIYO \\
\hline 18 & FONI PRAMESTI \\
\hline 19 & GEA APRINDA SANTYADEWI \\
\hline 20 & ILHAM LINTANG SYAFAWI \\
\hline
\end{tabular}

Tabel 5. Nama Kelompok 5

\begin{tabular}{|l|ll|}
\hline & INTAN ANITA \\
21 & PUSPANINGRUM & \\
\hline 22 & INTAN HERLYANA PUTRI \\
\hline 23 & KARISMA SANDHIKA PUTRA \\
\hline 24 & LOIS JESSICA CALISTA \\
\hline 25 & LUTFIANSYAH ADITYA VANJALU \\
\hline
\end{tabular}

Tabel 6. Nama Kelompok 6

\begin{tabular}{|l|l|}
\hline 26 & MUHAMMAD BINTANG AMINUDIN \\
\hline 27 & NURUL AULIA OKTAVIANI \\
\hline 28 & RIEZANG ADITYA EKA SAPUTRA \\
\hline 29 & RIVA ALFINA BERLIANDA \\
\hline 30 & SUTAN DIJAVANTHA
\end{tabular}


Tabel 7. Nama Kelompok 7

\begin{tabular}{|l|l|}
\hline 31 & TEGAR PRAMUDITA \\
\hline 32 & TIKA DEVIANA ASTUTI \\
\hline & WASKITO GALANG ESTU \\
33 & WICAKSONO \\
\hline 34 & YUDHA AJI PAMUNGKAS \\
\hline 35 & YUNUS SARUL \\
\hline 36 & YUSAK FAQIH WIBOWO \\
\hline
\end{tabular}

Guru meminta siswa menjelaskan Teknik Vokal. Siswa cukup memperhatikan hal ini. Kemudian guru memutar Film Nyanyian Indonesia Raya. Siswa cukup memperhatikan tayangan Film Nyanyian Indonesia Raya. Guru penjelasan Lagu Indonesia Raya meliputi lirik dan makna lagu dengan baik. Namun Siswa kurang memperhatikan tayangan Film Nyanyian Indonesia Raya.

\section{3) Kegiatan Penutup}

Pada kegiatan penutup, guru bersama siswa mengambil kesimpulan. Guru menulis tentang pentingnya seni musik yang harus dipertunjukkan. Proses mengambilan kesimpulan ini cukup baik, cukup lancar. Guru memberi tes. Siswa mengerjakan tes.

\section{Pengamatan}

Pada akhir setiap siklus siswa diberi tes. Sedangkan pada saat pembelajaran berlangsung pengamat mengamati siswa dan guru. Hasil tes dan pengamatan tersebut:

1) Rata-rata kelas 78,89. Dari 36 siswa, yang tuntas 28 siswa dan yang tidak tuntas 7 siswa. Ini berarti ketuntasan kelas 80,56\%. Hal ini menunjukkan hasil belajar siswa secara klasikal belum tuntas.

2) Rata-rata kemampuan guru dalam mengelola pembelajaran $(\mathrm{TKG})=1,91$. Hal ini menunjukkan bahwa kualifikasi kemampuan guru "Cukup".

3) Rata-rata aktifitas siswa (TAS) $=1,73$. Hal ini menunjukkan aktifitas siswa "cukup".

\section{Refleksi}

Dalam pelaksanaan kegiatan pembelajaran diperoleh informasi dari hasil pengamatan sebagai berikut:

1) Prestasi Belajar Siswa

Hasil belajar siswa secara klasikal belum tuntas. Walaupun belum tuntas, sudah ada peningkatan prestasi belajar. Guru perlu meningkatkan kualitas Gabungan teknik film dan demonstrasi agar prestasi belajar siswa dapat lebih meningkat, sehingga hasil belajar siswa secara klasikal dapat menjadi tuntas.

2) Kemampuan guru dalam mengelola pembelajaran

a. Guru kurang dalam memotivasi Siswa. Penyampaian mengenai tujuan dan langkahlangkah pembelajaran kurang lengkap, sehingga siswa kurang termotivasi dalam pembelajaran ini. Guru sebaiknya menyampaikan informasi mengenai tujuan dan langkah-langkah pembelajaran lebih lengkap lagi.

b. Guru kurang baik dalam mengadakan tanya jawab dengan Siswa. tanya jawab dengan Siswa berlangung monoton. Siswa kurang bergairah dalam tanya jawab ini.

c. Guru kurang dalam memberi masing-masing kelompok untuk mempraktikkannya. Agar siswa lebih termotivasi, guru sebaiknya menginformasikan tentang kegiatan secara terperinci. 


\section{3) Aktifitas siswa dalam pembelajaran}

a. Siswa kurang baik dalam mendengarkan informasi dari guru. Guru harus lebih baik lagi dalam menyampaikan informasi agar siswa bergairah untuk mendengarkannya.

b. Siswa kurang Termotivasi. Guru harus lebih baik lagi dalam menyampaikan penjelasan.

c. Siswa kurang Mengadakan Tanya jawab dengan guru. Guru harus memberi semangat pada siswa, sehingga siswa bersemangat dalam Tanya jawab.

d. Siswa kurang memperhatikan penjelasan Lagu Indonesia Raya meliputi lirik dan makna lagu. Guru harus lebih baik lagi dalam memberi penjelasan Lagu Indonesia Raya meliputi lirik dan makna lagu..

\section{B. Siklus II}

\section{Perencanaan}

Uraian lengkap rencana pembelajaran terdapat pada lampiran. Disamping membuat RPP penulis: Menyiapkan sejumlah pertanyaan yang akan dilontarkan pada kelompok siswa dan menjelaskan pada siswa tentang tugas yang harus dikerjakan. Sedangkan diskusi dengan teman sejawat dilakukan untuk menentukan hari tanggal pelaksanaan pembelajaran siklus II. Selain itu diskusi tentang penyusunan lembar pengamatan, aspek-aspek yang perlu diamati.

\section{Tindakan}

\section{1) Kegiatan Awal}

Langkah pertama dalam metode ini adalah menginformasikan tentang kegiatan dan tujuan pembelajaran. Guru menyampaikan tentang sekilas tentang kegiatan pembelajaran yang meliputi garis besar langkah-langkahnya. Guru juga menyampaikan sekilas tentang tujuan pembelajaran. Siswa kurang memperhatikan apa yang disampaikan guru. Para siswa masih ada yang bergurau sendiri. Beberapa siswa bahkan ada yang ijin keluar dengan alasan ke belakang. Siswa kelihatan tidak termotivasi dengan adanya pembelajaran ini.

\section{2) Kegiatan Inti}

Langkah pertama dalam kegiatan ini adalah guru memutar Film Sejarah Lahirnya Indonesia Raya. Siswa sangat memperhatikan tayangan Film Sejarah Lahirnya Indonesia Raya. Kemudian, guru mengadakan tanya jawab dengan Siswa. Siswa bersemangat dalam mengadakan tanya jawab dengan guru.

Langkah selanjutnya dalam kegiatan ini adalah guru memutar Film Teknik Vokal. Siswa memperhatikan tayangan Film Sejarah Teknik Vokal. Guru menjelaskan Teknik Vokal dengan sangat baik. Siswa memperhatikan penjelasan Teknik Vokal yang siampaikan guru. Setelah menjelaskan Teknik Vokal, guru membagi siswa menjadi 7 kelompok masing-masing 5 atau 6 siswa. Siswa Membagi kelompok praktek vokal menjadi 7 kelompok masing-masing 6 atau 7 siswa (kelompok 1 sampai 6 terdiri 5 siswa, sedangkan kelompok 7 terdiri 6 siswa). Guru membagi siswa dalam kelompok berdasar nomor absen. Adapun nama-namanya:

Tabel 8. Kelompok 8

\begin{tabular}{|l|l|}
\hline 1 & AANG ADRIAN FIRMANSYAH \\
\hline & $\begin{array}{l}\text { ANCHI ALIFIA AZZAHRA } \\
2\end{array}$ \\
\hline 3 & ANOVADIKA \\
\hline 4 & ANINDYTO PUTRA WIBISONO \\
\hline 5 & ARUM PURSILASARI \\
\hline
\end{tabular}

Tabel 9. Kelompok 9

\begin{tabular}{|l|l|}
\hline 6 & AYLUL FAJRINNIAR 'AINIYAH \\
\hline 7 & BILQIS SALMA GINTAJATI \\
\hline 8 & BINTANG DEWANTO \\
\hline 9 & BRIAN SYAFRIANSYAH \\
\hline
\end{tabular}


10 DEA CARISSA OVILIA

Tabel 10. Kelompok 10

\begin{tabular}{|l|l|}
\hline 11 & DELA BINTANG WULANDARI \\
\hline 12 & DHIMAS PANDU WIJAYA \\
\hline 13 & ELIYANO ATMAJA TIMUR \\
\hline 14 & ENJELLINA APRIANTI \\
\hline 15 & FERRY HENDRA WIJAYA \\
\hline
\end{tabular}

Tabel 11. Kelompok 11

\begin{tabular}{|l|l|}
\hline 16 & FINA PRAMESTA \\
\hline 17 & FIRMANNANDA WIRA SUBAGIYO \\
\hline 18 & FONI PRAMESTI \\
\hline 19 & GEA APRINDA SANTYADEWI \\
\hline 20 & ILHAM LINTANG SYAFAWI \\
\hline
\end{tabular}

Tabel 12. Kelompok 12

\begin{tabular}{|l|l|}
\hline & INTAN AYU ANITA \\
21 & PUSPANINGRUM \\
\hline 22 & INTAN HERLYANA PUTRI \\
\hline 23 & KARISMA SANDHIKA PUTRA \\
\hline 24 & LOIS JESSICA CALISTA \\
\hline 25 & LUTFIANSYAH ADITYA VANJALU \\
\hline
\end{tabular}

Tabel 13. Kelompok 13

\begin{tabular}{|l|l|}
\hline 26 & MUHAMMAD BINTANG AMINUDIN \\
\hline 27 & NURUL AULIA OKTAVIANI \\
\hline 28 & RIEZANG ADITYA EKA SAPUTRA \\
\hline 29 & RIVA ALFINA BERLIANDA \\
\hline 30 & SUTAN DIJAVANTHA \\
\hline
\end{tabular}

Tabel 14. Kelompok 14

\begin{tabular}{|l|l|}
\hline 31 & TEGAR PRAMUDITA \\
\hline 32 & TIKA DEVIANA ASTUTI \\
\hline 33 & WASKITO GALANG ESTU \\
\hline 34 & WICAKSONO \\
\hline 35 & YUNUA AJI PAMUNGKAS SARUL \\
\hline 36 & YUSAK FAQIH WIBOWO \\
\hline
\end{tabular}

Guru meminta siswa menjelaskan Teknik Vokal. Siswa cukup memperhatikan hal ini. Kemudian guru memutar Film Nyanyian Indonesia Raya. Siswa sangat memperhatikan tayangan Film Nyanyian Indonesia Raya. Guru penjelasan Lagu Indonesia Raya meliputi lirik dan makna lagu dengan sangat baik. Namun Siswa kurang memperhatikan tayangan Film Nyanyian Indonesia Raya.

\section{4) Kegiatan Penutup}

Pada kegiatan penutup, guru bersama siswa mengambil kesimpulan. Guru menulis tentang pentingnya seni musik yang harus dipertunjukkan. Proses mengambilan kesimpulan ini dengan sangat baik, cukup lancar. Guru memberi tes. Siswa mengerjakan tes. 


\section{Pengamatan}

Pada akhir setiap siklus siswa diberi tes. Sedangkan pada saat pembelajaran berlangsung pengamat mengamati siswa dan guru. Hasil tes dan pengamatan tersebut:

1) Rata-rata kelas 80,69. Dari 36 siswa yang tuntas 33 siswa dan yang tidak tuntas 3 siswa. Ini berarti ketuntasan kelas 91,67 \%. Hal ini menunjukkan hasil belajar siswa secara klasikal sudah tuntas.

2) Rata-rata kemampuan guru dalam mengelola pembelajaran $(\mathrm{TKG})=3,09$. Hal ini menunjukkan bahwa kualifikasi kemampuan guru "baik".

3) Rata-rata aktifitas siswa (TAS) $=2,91$. Hal ini menunjukkan aktifitas siswa " baik".

\section{Refleksi}

Dalam pelaksanaan kegiatan belajar mengajar diperoleh informasi dari hasil pengamatan sebagai berikut:

1) Prestasi Belajar Siswa

Hasil belajar siswa secara klasikal sudah tuntas. Siklus selanjutnya tidak perlu dilakukan. Walaupun sudah tuntas, sudah ada peningkatan prestasi belajar. Guru perlu meningkatkan kualitas Gabungan teknik film dan demonstrasi agar prestasi belajar siswa dapat lebih meningkat lagi.

2) Kemampuan guru dalam mengelola pembelajaran

a. Guru sangat baik dalam menjelaskan Teknik Vokal.

b. Guru sangat baik dalam memberi penjelasan Lagu Indonesia Raya meliputi lirik dan makna lagu.

c. Guru sangat baik dalam guru bersama siswa mengambil kesimpulan. Hal lainnya sudah baik

\section{3) Aktifitas siswa dalam pembelajaran}

a. Siswa sangat memperhatikan tayangan Film Sejarah Lahirnya Indonesia Raya.

b. Siswa sangat memperhatikan tayangan Film Nyanyian Indonesia Raya.. Hal lain sudah baik.

\section{Pembahasan}

1. Gabungan teknik film dan demonstrasi dapat meningkatkan kemampuan siswa dalam Menyanyikan Lagu Indonesia Raya

Hasil penelitian ini menunjukkan bahwa Gabungan teknik film dan demonstrasi pada materi "Menyanyikan Lagu Indonesia Raya" memiliki dampak positif dalam meningkatkan prestasi belajar siswa. Hal ini dapat dilihat dari semakin mantapnya pemahaman siswa terhadap materi yang disampaikan guru (rata-rata kelas dari siklus I dan ke II) yaitu masing-masing 78,89 dan 80,69. Pada siklus II kelas dalam keadaan tuntas.

\section{Gabungan teknik film dan demonstrasi dapat meningkatkan kemampuan guru mengelola pembelajaran}

Dari data yang tersaji, kemampuan guru mengelola Gabungan teknik film dan demonstrasi dapat diketahui bahwa TKG $=3,09$. Pembelajaran dikatakan efektif ditinjau dari kemampuan guru mengelola Gabungan teknik film dan demonstrasi pada materi "Menyanyikan Lagu Indonesia Raya" berada pada kategori minimal baik atau 2,4 $\leq \mathrm{TKG}<3,2$. Dengan demikian kemampuan guru dalam Gabungan teknik film dan demonstrasi terpenuhi.

\section{Gabungan teknik film dan demonstrasi dapat meningkatkan kemampuan Aktivitas Siswa Dalam Pembelajaran}

Dari data yang tersaji, aktifitas siswa dalam Gabungan teknik film dan demonstrasi dapat diketahui bahwa TAS $=2,91$. Pembelajaran dikatakan efektif ditinjau dari aktifitas siswa dalam Gabungan teknik film dan demonstrasi pada materi "Menyanyikan Lagu Indonesia 
Raya" berada pada kategori minimal baik atau $2,4 \leq \mathrm{TAS}<3,2$. Dengan demikian kualifikasi aktifitas siswa dalam Gabungan teknik film dan demonstrasi terpenuhi.

\section{KESIMPULAN}

Meningkatkan motivasi mengajar guru dan belajar siswa dalam setiap melaksanakan kegiatan pembelajaran di sekolah, terbukti dengan nilai setiap siklus yang senantiasa mengalami perubahan secara signifikan, meningkatkan wawasan, pengetahuan, sikap dan keterampilan guru dalam melaksanakan proses pembelajaran kepada siswa, terbukti dengan guru senantiasa mengalami perkembangan dalam menyajikan pembelajaran yang lebih menarik dan berkualitas bagi para siswanya, dan teridentifikasi dan terpecahkannya setiap permasalahan pembelajaran yang terjadi pada setiap siklus berdasarkan analisis data dan pengkajian melalui perolehan nilai yang dianggap kurang memenuhi kriteria yang telah ditetapkan.

\section{DAFTAR PUSTAKA}

Adhityo, D dan Astika, I Gusti Agung Anom. Bunyi Merdeka Sejarah Sosial dan Tinjauan Musikologi Lagu Kebangsaan Indonesia Raya. Edisi Pertama. Ebook. Juli 2017.

Ayoana. (2010). Definisi Film. (http://ayoana.tumblr.com/ post/post/390644418/defisifilm). Diakses pada hari Jumat tgl 9 Februari 2018

Bahri, Syaiful \& Zain, Aswan (2005). Strategi Belajar Mengajar. Jakarta : Rineka Cipta.

Balai Pustaka. (2001). Kamus Besar Bahasa Indonesia, Jakarta, Balai Pustaka.

Departemen Pendidikan dan Kebudayaan. (1994). Petunjuk Pelaksanaan Proses Belajar Mengajar, Jakarta. Balai Pustaka.

Depdiknas. (2004.) Sistem Penilaian Kurikulum 2004, Jakarta, Depdiknas.

Hasibuan. J.J. dan Moerdjiono. (1998). Proses Belajar Mengajar. Bandung: Remaja Rosdakarya.

Kementerian Pendidikan dan Kebudayaan Direktorat Jenderal Kebudayaan Direktorat Kesenian

Kemmis, S. dan Mc. Taggart, R. (1988). The Action Research Planner. Victoria Dearcin University Press.

Margono, S. 1996. Metodologi Penelitian Pendidikan. Jakarta: Rineksa Cipta.

Muhamad Afandi, S.Pd., M.Pd Evi Chamalah, S.Pd., M.Pd Oktarina Puspita Wardani, S.Pd., M.Pd. (2013). Model dan Metode Pembelajaran di Sekolah. Semarang : Unissula Press Pramayudha Yudha. Buku Pintar olah Vokal Buku Biru. 2010

Sardiman, A.M. (2001). Interaksi dan Motivasi Belajar Mengajar, Jakarta, Grafindo Persada. Soekamto, Toeti. (1997). Teori Belajar dan Model Pembelajaran. Jakarta: PAU-PPAI, Universitas Terbuka.

Sudjana, N dan Ibrahim. (1989). Penelitian dan Penilaian Pendidikan. Bandung: Sinar Baru. Undang-undang Nomor 24 tahun 2009 